\title{
DESIGN AND IMPLEMENTATION OF LENSES FOR SHAPING THE BEAM OF MiLLIMETER WAVES IN FREE SPACE
}

\author{
Petr Skočík , Jiří Korbel, Petr Neumann \\ Tomas Bata University in Zlín, Faculty of Applied Informatics, Nad Stráněmi 4511, 76005 Zlín, Czech Republic
}

\begin{abstract}
This paper deals with the beam forming of the electromagnetic waves with a wavelength in the order of millimeters. The goal is to design, implement and verify the dielectric lens of a suitable material for shaping the beam of millimeter waves to the plane wave and refine and analyze signal frequency range from $220 \mathrm{GHz}$ to $325 \mathrm{GHz}$. For this purpose a specialized measuring workplace is used. It is equipped with the vector network analyzer ZVA67 by Rohde and Schwarz. It also includes millimeter wave converter for achieving the frequency range up to $325 \mathrm{GHz}$. The measurement is performed in free space with respective circular antennas. Three measurement methods are used to verify the proper function of developed lenses. The aim is to get the system of dielectric lenses in the millimeter band, which would replace the complicated system of mirrors. In the implementation of the system it is necessary to pay attention to the accuracy of manufacture and the quality of the chosen material.
\end{abstract}

Keywords: Plane wave; Beam forming; Lenses; Vector network analyzer; Circular antenna
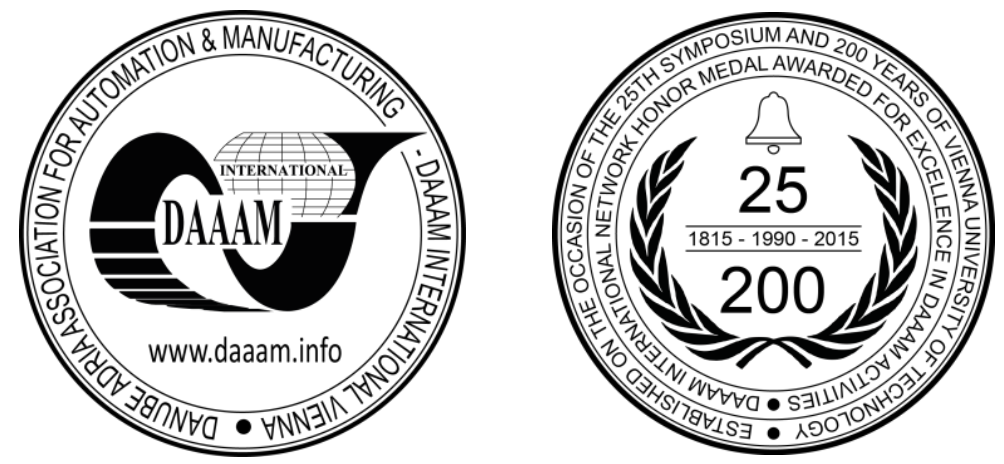

This Publication has to be referred as: Skocik, P[etr]; Korbel, J[iri] \& Neumann, P[etr] (2016). Design and Implementation of Lenses for Shaping the Beam of Millimeter Waves in Free Space, Proceedings of the 26th DAAAM International Symposium, pp.0027-0034, B. Katalinic (Ed.), Published by DAAAM International, ISBN 978-3-90273407-5, ISSN 1726-9679, Vienna, Austria DOI:10.2507/26th.daaam.proceedings.004 


\section{Introduction}

Development of the society brings new demands in all areas of human research. There have been several phases of such a significant development in the past. Currently, a significant progress is undergoing in information technologies which is related to developments in microelectronics and especially in equipment used in computing and control technologies. Unfortunately, such development has also its negatives. One of the problems is certainly functional reliability of these devices which is influenced not only by the accuracy and quality of the production itself, but also by the external influences acting on the final device. Currently, this problem escalates as the surrounding environment is overburdened by a number of interfering signals. Many of these signals are "wanted", for example a wireless communication of different devices, but there are also "unwanted" signals caused by uncontrolled radiation of devices whose design has not considered this issue. All these signals are then received by other devices which may cause technological malfunctions or accidents on some of them. If it is a devices having key importance in complex processes, such failure can lead to substantial material damage or even result in the loss of human life. A typical representative of such devices is for example equipment used in air traffic control and the aviation industry itself.

Therefore, it is an effort to prevent possible equipment failure at the time of its design and construction. It means designing devices to be able to function properly even in an environment with any source of electromagnetic interference. Of course the economic implications arise. For example, an aircraft can fail in the final certification process when this fact is not considered in its design. This involves the return of the prototype back to the initial stage of development including all the related costs. Since this is a relatively new issue in the design of small aircraft the manufacturers are not always prepared adequately on such tests. To obtain certification, it is necessary to deliver a functional prototype of the aircraft on which the certification tests are performed. These tests include the measurement of resistance to electromagnetic interference. Today, modern aircraft uses composite materials. These materials are very well described in terms of the mechanical properties. Unfortunately, this does not apply to their electrical properties. Emerging specialized laboratory at the Faculty of Applied Informatics will focus on solving this lack of knowledge from the perspective of research on the influence of small defects on electromagnetic shielding effectiveness of composite materials and its assessment in terms of the protection of avionics in the electromagnetic environment. It will also focus on the measurement of complex permittivity in free space to specify electrical characteristics of composite materials in the frequency range from $220 \mathrm{GHz}$ to $325 \mathrm{GHz}$. For this it is necessary to consider the issue of forming the beam of electromagnetic waves to a plane wave [1]. For this purpose, the most commonly used system utilizes mirror reflection. However, this contribution will focus on the design and implementation of dielectric lenses to replace the complicated system of mirrors.

\section{Design and implementation of lenses}

It was necessary to choose a suitable dielectric material for the production of lenses. The impact of the material on the electromagnetic radiation must be considered. Also the material must have good machinability and workability. Polytetrafluorethylene (Teflon) was selected as a suitable material. It has high chemical resistance, good sliding properties, aging resistance, high temperature resistance, etc. It is also non-toxic in the temperature range from $-70{ }^{\circ} \mathrm{C}$ to $250{ }^{\circ} \mathrm{C}$. It is important that it is easily machined and also frequency-invariant in term of its properties and the dispersion of light does not occur with it [2], [3]. Since the proposed lenses will be used for frequency range from $220 \mathrm{GHz}$ to 325 $\mathrm{GHz}$ a test measurement was performed with a sample of Teflon. The aim was to check the attenuation of the material in the given frequency range. An emerging laboratory equipped with spectrum analyzer R\&S®ZVA67 was used for this purpose. The frequency range of the analyzer was extended by frequency converters with corresponding circular horn antennas as can be seen in Fig. 1. The result of the measurement is shown in Fig. 2. It can be seen that the attenuation of the Teflon sample at a given frequency was around $3 \mathrm{~dB}$.

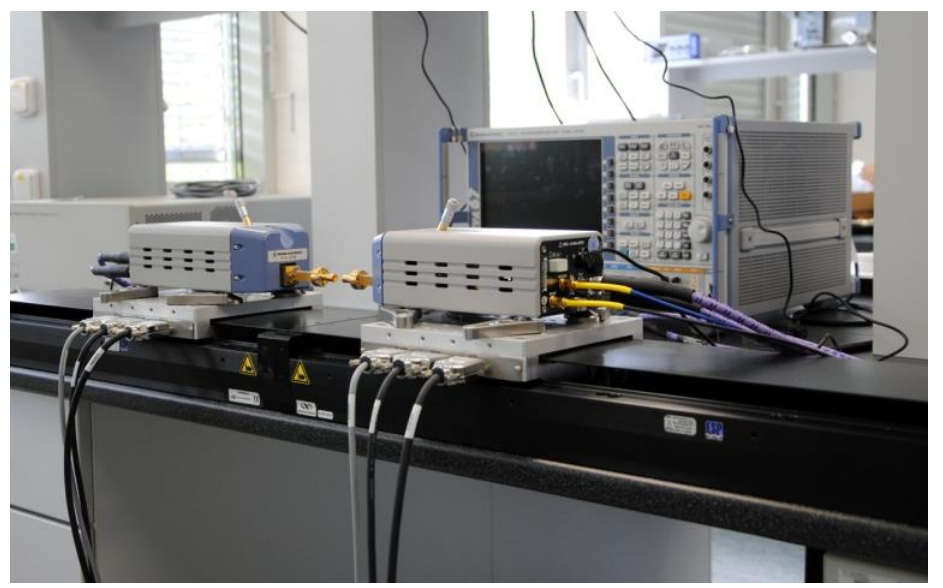

Fig. 1. Vector network analyzer with frequency converters [10] 


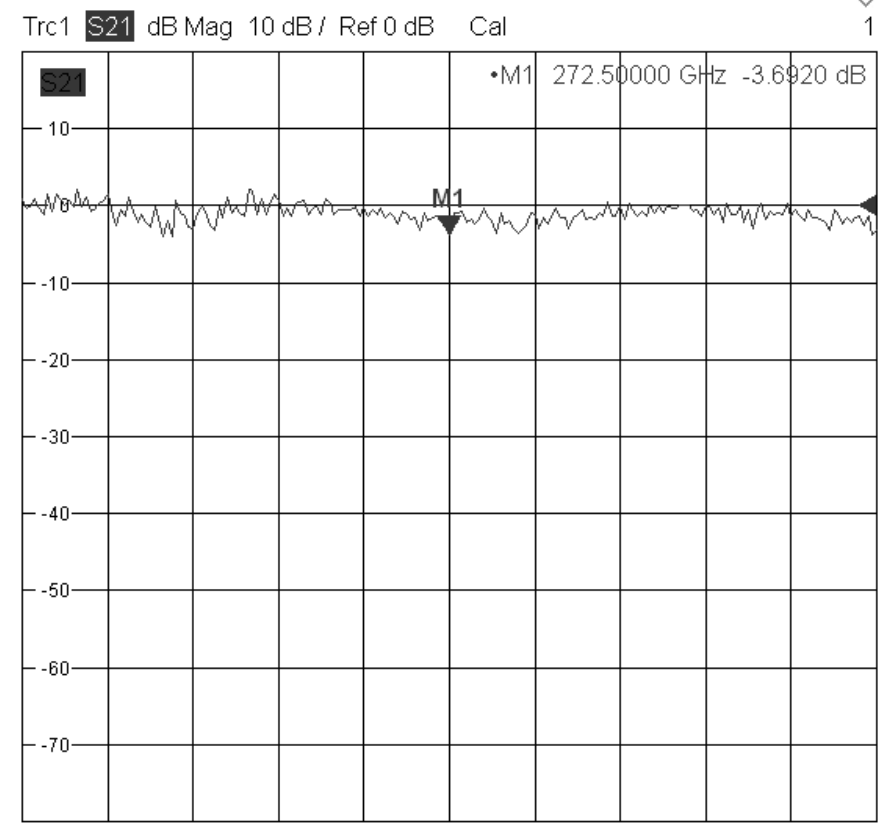

Ch1 A.rb fb Start $219.999999999 \mathrm{GHzl}$ dBm

Stop $325 \mathrm{GHz}$ 5/14/2015, 9:43 AM

Fig. 2. Attenuation of the Teflon sample

The goal was to design two lenses for next experiments. The design is based on biconvex converging lens because there is plenty theoretical knowledge about it. The lens diameter was chosen based on the requirements from the manufacturer. They used a Teflon rod of diameter of $50 \mathrm{~mm}$ for production [4]. The radius was also chosen by the production possibilities. The remaining parameters according to the Fig. 3 are calculated from the equations [5]:

$$
\begin{aligned}
& s_{1}=r_{1}-\sqrt{r_{1}^{2}-\left(\frac{d}{2}\right)^{2}}=0.1-\sqrt{0.1^{2}-\left(\frac{0.05}{2}\right)^{2}}=3.18 \mathrm{~mm} \\
& s_{2}=r_{2}-\sqrt{r_{2}^{2}-\left(\frac{d}{2}\right)^{2}}=0.1-\sqrt{0.1^{2}-\left(\frac{0.05}{2}\right)^{2}}=3.18 \mathrm{~mm} \\
& t_{s}=s_{1}+s_{2}+t_{o}=3.18+3.18+10=16.36 \mathrm{~mm}
\end{aligned}
$$
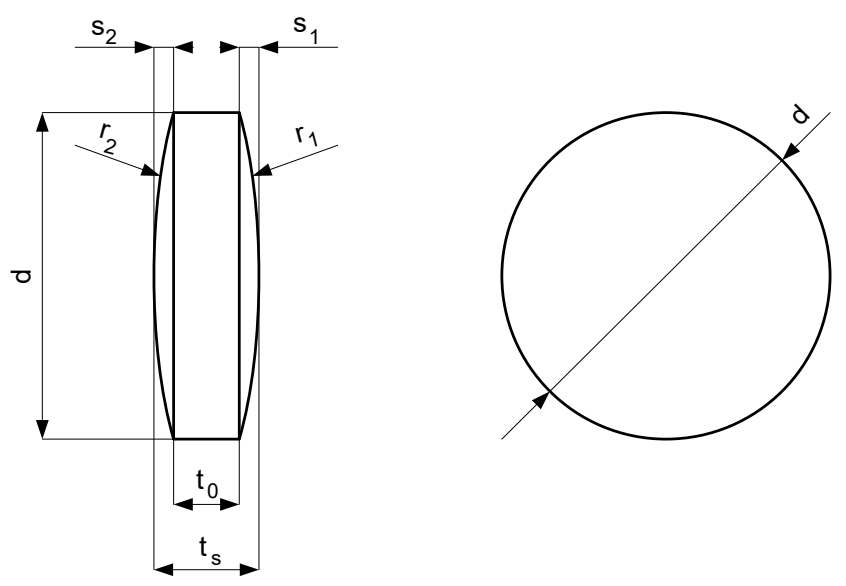

Fig. 3. Front and side of biconvex lens

Two plano-convex lenses (Fig. 4) were derived from the biconvex lens (Fig. 3). 

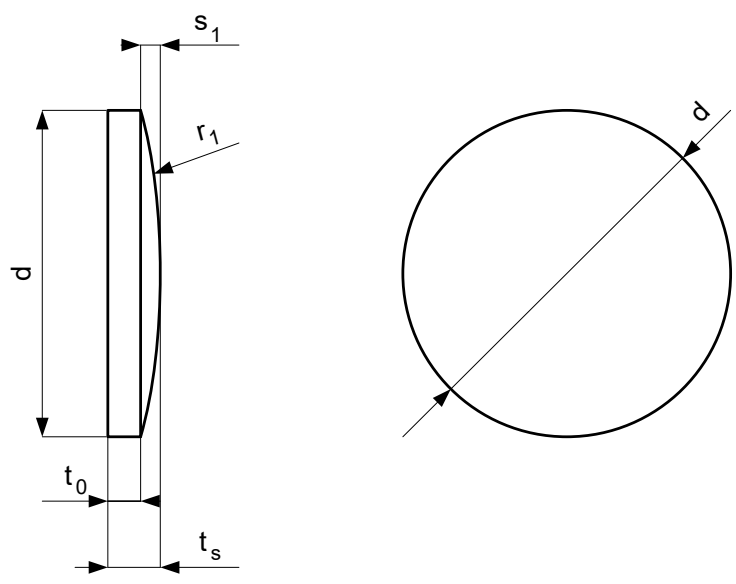

Fig. 4. Front and side of plano-convex lens

Focal length of the biconvex lens is given by [6]:

$\frac{1}{f}=(n-1)\left(\frac{1}{r_{1}}+\frac{1}{r_{2}}+\frac{t_{s}(n-1)}{n r_{1} r_{2}}\right)$

As can be seen it is necessary to know the refractive index of the material from which the lens is produced. It can be calculated from the permittivity of Teflon which is $\varepsilon=2.1$ by the equation:

$n=\sqrt{\varepsilon}$

The refractive index from (5) is $n=1.449$ and the focal length from (4) is $f=109 \mathrm{~mm}$. The focal length for the lens in Fig. 4 is based on the equation for thin lens since the thickness is relatively small compared with the radius. Parameter $\mathrm{r} 1$ is infinite because one side of the lens is flat. The focal length is the given by [7]:

$\frac{1}{f}=(n-1)\left(\frac{1}{r_{1}}+\frac{1}{r_{2}}\right)$

After substituting lens parameters into equation (6) the focal length is $\mathrm{f}=223 \mathrm{~mm}$.

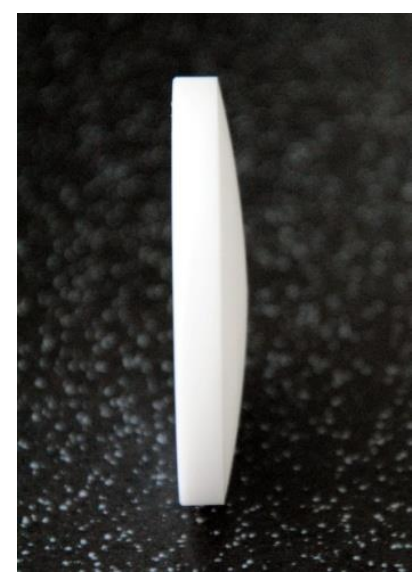

Fig. 5. Manufactured plano-convex Teflon lens [10]

\section{Verification of lenses}

Lenses were made with high accuracy and quality. The difference between them is in the order of thousandths to hundredths of a millimetre. After placing the lens in front of source of electromagnetic waves the following situations can occur [8]: 


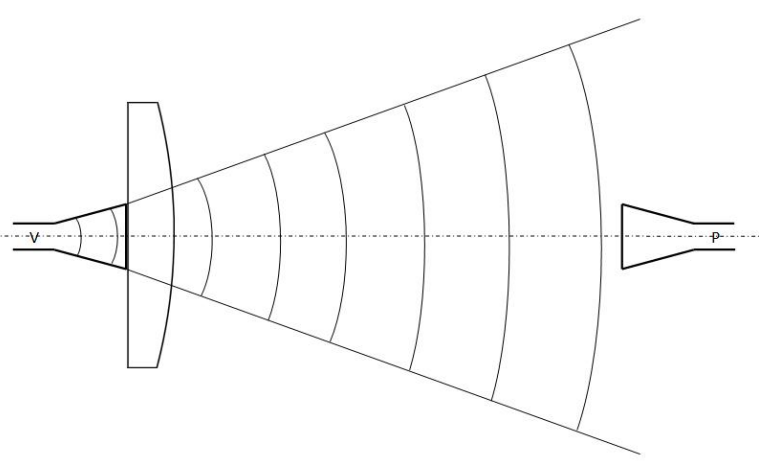

Fig. 6. Lens placed before the focal point

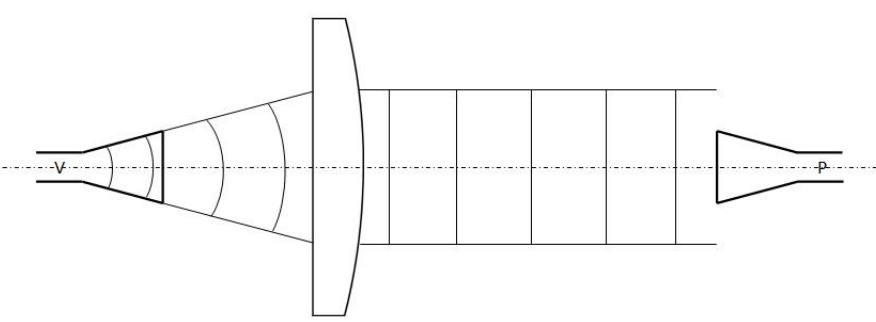

Fig. 7. Lens placed at the focal point

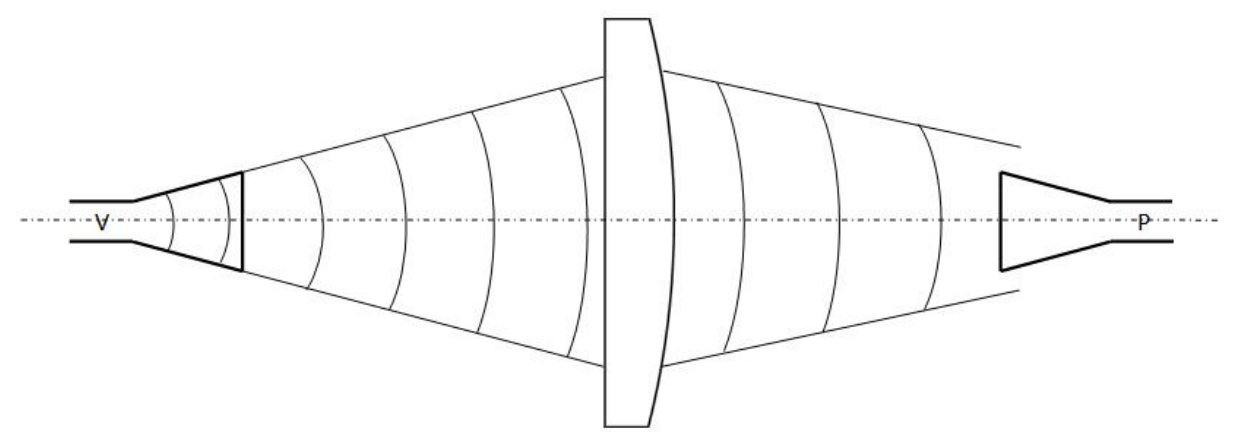

Fig. 8. Lens placed behind the focal point

As can be seen in Fig. 6-8 the lens must be placed at the focal point of the signal source, which is a circular antenna mounted on the frequency converter. Otherwise, the beam of electromagnetic waves will diverge (Fig. 6) or converge (Fig. 8) which will not create the desired plane wave.

The correct function of the manufactured lenses was verified on the laboratory equipment (Fig. 1) which consists of the vector network analyzer R\&S®ZVA67 and frequency converters R\&S®ZVA-Z325. This set with corresponding circular antennas (Fig. 9) allows the measurement in frequency range from $220 \mathrm{GHz}$ to $325 \mathrm{GHz}$. There are also two Newport high performance linear stages connected to one control unit.

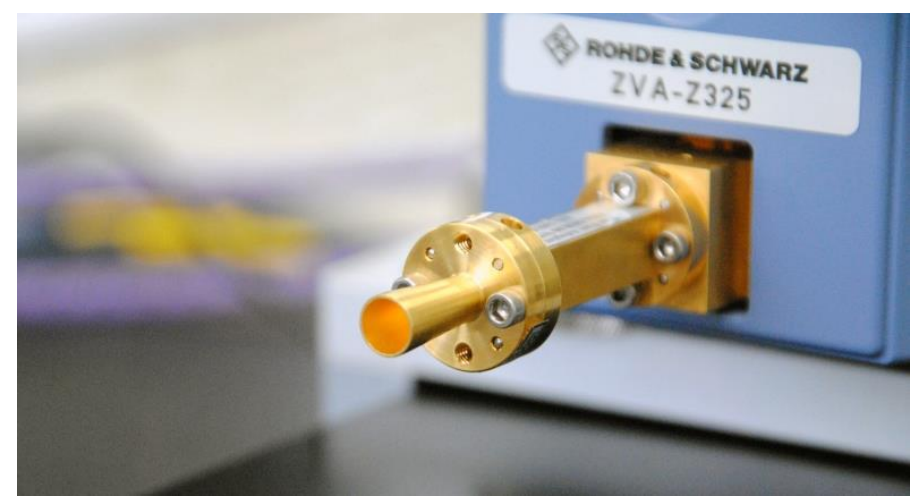

Fig. 9. Circular horn antenna [10] 
Before the measurement a TRL calibration was performed using the R\&S®ZV-WR03 calibration set [1], [4]. The workplace was also equipped with a special Pyrocam III (Fig. 10) camera. According to the specification it should allow to monitor electromagnetic waves in the measured frequency range. The camera allows monitoring of signals of different wavelengths using the appropriate replaceable filters. In this case a LDPE filter for terahertz area was used. The camera uses software Pyrocam III Control Console and BeamGate for the evaluation of results and also for control [9].

Unfortunately, after a series of measurements it has been found that this method is not suitable for detection of millimeter wave beam because the captured signal is too low.
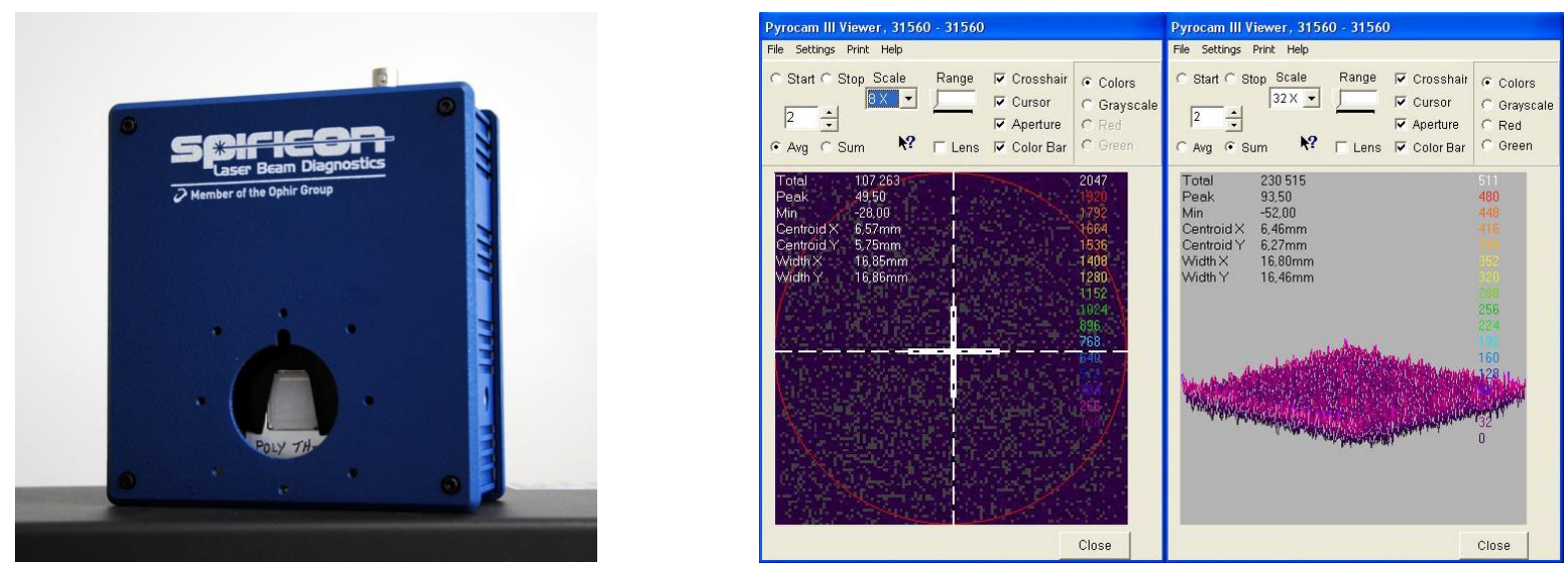

Fig. 10. Spiricon Pyrocam III camera and look of the captured signal [10]

The next possible method was direct measurement by Ophir VEGA (Fig. 11). This device has higher sensitivity than Pyrocam III. Ophir VEGA uses external sensor based on thermocouples. The result can be seen also in Fig. 11. When measuring in the vicinity of the transmitting antenna the measured power has value of approximately 141 $\mu \mathrm{W}$.
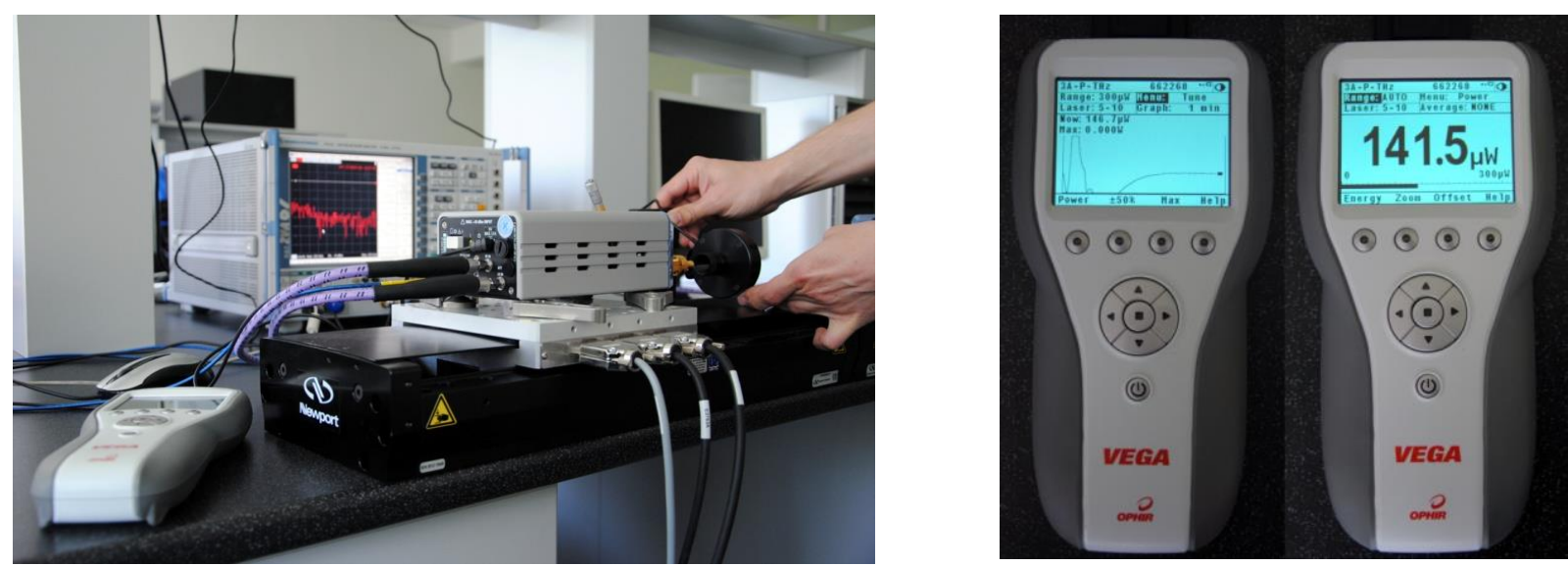

Fig. 11. Direct measurement by Ophir VEGA [10]

Unfortunately, this method of measurement has proved unsuitable because of high sensitivity. With increasing distance of the sensor from signal source the power of captured signal grew because it was influenced by the surroundings. As already stated the sensor utilizes the principle of the thermocouple, thus it is a thermal sensor and its sensitive surface senses the thermal radiation of surrounding objects.

Another option was to measure using R\&S®ZVA67 analyzer. The aim was to determine the profile of the emitted beam of millimeter waves using displacement of receiving antenna and changing the position of the lens on the route between the transmitting and receiving antenna. The assumption was that the transmitting antenna is stationary and only the receiving antenna will move. The precise feed was ensured by one of the linear stages (Fig. 12). The deflection was set to $50 \mathrm{~mm}$ to the right and left from center and feed increments of $5 \mathrm{~mm}$. Upon detection of beam shape without using the lens, a series of measurements with the lens followed. It is shifted between the antennas by 20 mm step away from the transmitting antenna. The first position of the lens was just behind the transmitting antenna. Measurements were performed for the frequency of $220 \mathrm{GHz}$. 


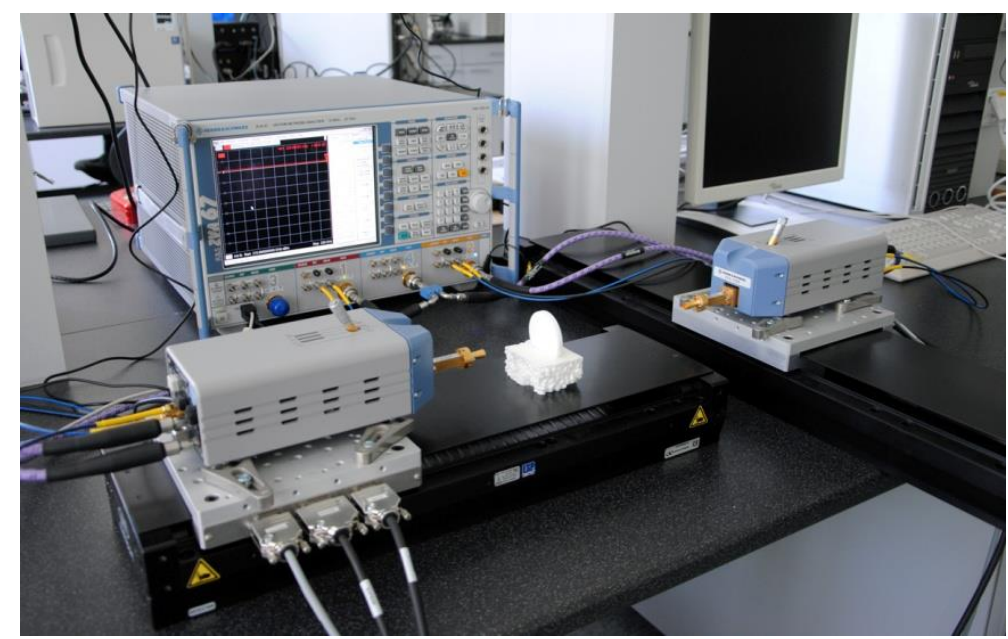

Fig. 12. Verification of the manufactured lens [10]

The results of individual measurements were processed in graphic form. The goal was to find the largest step change that occurred precisely at the focal distance, wherein the lens shaped the waves into plane wave. Dependencies have a shape resembling the inverted letter U. If it expands, the situation corresponds with Fig. 6 where the lens is before the focal point. When it narrows, the situation is similar as in Fig. 8 where the lens is behind the focal point. Selected waveforms can be seen in Fig. 13.

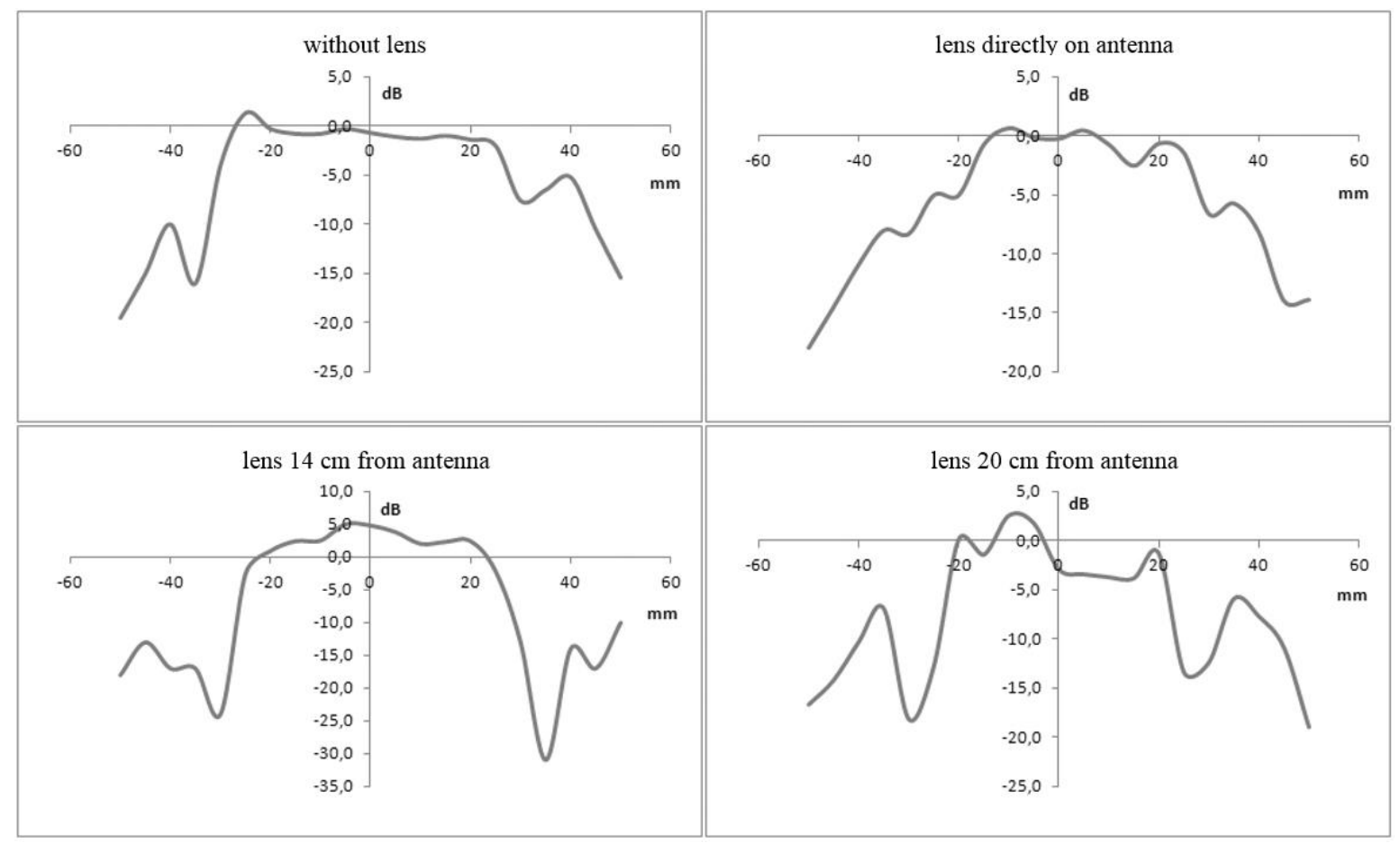

Fig. 13. Selected results obtained from the measurement

\section{Conclusion}

The aim of this paper was to design and develop the lenses for forming the beam of millimetre electromagnetic waves to the plane wave. The lenses were manufactured from Teflon. It was chosen as the suitable dielectric material for its electrical and mechanical properties. High precision machining and high material quality was requested in the production. Three methods were used for verification of the lens proper function. Unfortunately, only one of them was proven suitable. This method was based on measuring of the beam profile of emitted electromagnetic waves. The focal length of manufactured plano-covex lens was different in theory and in measurement. This difference was caused by manual measurement which require precise positioning and also by the lens material which can have inhomogeneity in the structure. The future research will be focused on design and development of positioning device for precise manipulation with the lenses. 


\section{References}

[1] ORLOB, Christian, Tobias REINECKE, Eckhard DENICKE, Bernd GECK a Ilona ROLFES. Compact Unfocused Antenna Setup for X-Band Free-Space Dielectric Measurements Based on Line-Network-Network Calibration Method. IEEE Transactions on Instrumentation and Measurement [online]. 2013, 62(7): 1982-1989 [cit. 2015-0419]. DOI: 10.1109/TIM.2013.2246905. ISSN 0018-9456. Available from: http://ieeexplore.ieee.org/lpdocs/epic03/wrapper.htm?arnumber=6490399

[2] Teflon Characteristic (in Czech). Hansanet s.r.o. [online]. 2014 [cit. 2015-04-19]. Available from: http://www.hansanet.cz/ clanek/29/Charakteristika-teflonu.aspx

[3] Teflon was Invented by Accident. Today I Found Out [online]. 2011 [cit. 2015-04-19]. Available from: http://www.todayifoundout.com/ index.php/2011/08/teflon-was-invented-by-accident/

[4] TOSAKA, Toshihide, Katsumi FUJII, Kaori FUKUNAGA a Akifumi KASAMATSU. Development of Complex Relative Permittivity Measurement System Based on Free-Space in 220-330-GHz Range. IEEE Transactions on Terahertz Science and Technology [online]. : 1-8 [cit. 2015-04-19]. DOI: 10.1109/TTHZ.2014.2362013. ISSN 2156-342x. Available from: http://ieeexplore.ieee.org/lpdocs/epic03/wrapper.htm?arnumber=6937218

[5] Production technology of spectacle lenses (in Czech). Faculty of Medicine, Masaryk University [online]. 2012 [cit. 2015-04-19]. Available from: http://is.muni.cz/do/rect/el/estud/lf/js12/vyroba_cocek/web/index.html

[6] Measuring the Magnification of Homemade Simple Microscope Lenses. Mic-UK [online]. 2007 [cit. 2015-04-19]. Available from: uk.org.uk/mag/artoct07/jd-lens.html

[7] HALLIDAY, David, Robert RESNICK a Jearl WALKER. Physics: university textbook of general physics. Ed. 1. Brno: VUTIUM, 2000, VII, p. 890-1032, ISBN 80-214-1868-0.

[8] BORN, Max and Emil WOLF. Principles of optics: electromagnetic theory of propagation, interference and diffraction of light. 7th expanded ed. New York: Cambridge University Press, 1999, 952 p., ISBN 0521639212.

[9] THZ beam profile: Pyroelectric Laser Profiler. Ophir Spiricon [online]. 2015 [cit. 2015-05-10]. Available from: http://www.ophiropt.com/ laser-measurement-instruments/beam-profilers/products/industrial-applications/thecameras/pyrocam

[10] ZAJÍC, Michal. The Design and Development Of a Lenses Kit for Shaping Millimeter Wave Beam Bundles. Zlín, 2015. Diploma thesis. Tomas Bata University in Zlín. 